\title{
A NEW APPROACH TO PULMONARY EMPHYSEMA
}

\author{
BY
}

OSLER A. ABBOTT, WILLIAM A. HOPKINS, WILLIAM E. VAN FLEIT, AND JOE S. ROBINSON

From the Department of Surgery (Division of Thoracic Surgery), Emory University School of Medicine, U.S.A. $\vec{\circ}$

[(RECEIVED FOR PUBLICATION NOVEMBER 11, 1952)

One of the unsolved problems of pulmonary disease is the complex entity of pulmonary emphysema. There is as yet no uniform acceptance of the aetiology of the illness. Therapy mainly consists of attempts to palliate certain factors in the illness rather than specifically to treat causative agents and stop the progress of the disease.

The following major problems are presented by the disease. First, can we define a reasonable aetiology? How does the disease progress, and what factors are involved in such progression? What are the earlier stages of pulmonary emphysema and how are they to be recognized? How can one discover localized areas of increased intrapulmonary pressure? What therapeutic methods are available relative to the disease, and what are their value? If surgery is used, what special anaesthesia-operative and post-operative-considerations are there? To try to answer some of these questions we have carried out a clinical study of 294 patients suffering from varying stages and degrees of pulmonary emphysema.

\section{aetiological Considerations}

A microscopic study of pathological material impresses with the atrophic character of pulmonary emphysema. Much attention has been drawn to the loss of elastic tissue. There is also an impressive change in the vascular bed; not only is there a loss of the finer radicals of the vascular bed in many areas, but a change in the wall of the blood vessels themselves is found. It would be interesting to know if it is a primary or secondary phenomenon. Pathologists are impressed with the similarity of the vascular change noted in such specimens and the changes noted in patients suffering from bronchiectasis. It is our personal impression that the vascular changes are secondary and do not represent a primary endarteritis. Considerable further investigation should be carried out to clarify this point. The major question, then, is, "What is the cause of the atrophic change in the lung?" Certainly, in some instances, the degenerative effects of age must play a role. However, there are many instances of emphysema in the younger age groups, so that some other factor must be primarily involved, at iv least in the pre-senile form.

The age distribution of our series is presented in $\vec{\sigma}$ Table I. The data were also studied in regard to the sex incidence of the disease, and a predominance of the illness in men was noted (Table II).

TABLE I

AGE DISTRIBUTION OF 294 CASES OF PULMONARY EMPHYSEMA

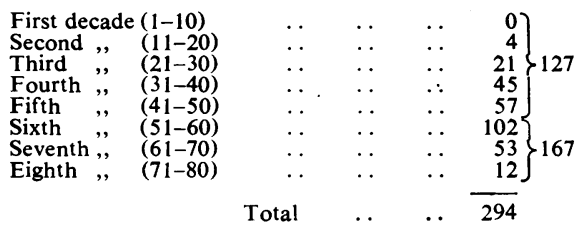

TABLE II

SEX DISTRIBUTION OF 294 CASES OF PULMONARY EMPHYSEMA

\begin{tabular}{|c|c|c|c|c|c|c|}
\hline$\underset{\text { Female }}{\text { Male }} . \cdots$ & 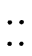 & $\begin{array}{l}\cdots \\
\cdots\end{array}$ & $\cdots$ & $\ddot{*}$ & $\begin{array}{l}\cdots \\
\cdots\end{array}$ & $\begin{array}{r}188 \\
61\end{array}$ \\
\hline Male (veterans) & & . & . & . & . & $\begin{array}{r}249 \\
45\end{array}$ \\
\hline Total s & tud & roup & . & . & . & 294 \\
\hline
\end{tabular}

Two hundred and forty-nine were seen in a hospital with equal admission rate for the two sexes. Forty-five men were seen at the Veterans' Hospital, where the admission ratio is 20 men to 1 woman

Considerable attention has been drawn in the past to a possible familial character in the disease, and the family histories of the patients involved were studied. This analysis is shown in Table III, and

TABLE III

ANALYSIS OF 107 CASES OF PULMONARY EMPHYSEMA ACCORDING TO FAMILY HISTORY

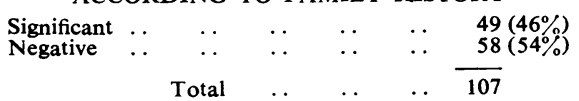

reveals that there were $46 \%$ of patients in whom a distinct family history of similar pulmonary disease $\frac{0}{\mathbb{D}}$ was presented. The patients were next studied in regard to possible or specific aetiological factors $\stackrel{\mathbb{Q}}{\square}$ involved. We were impressed clinically with the history of long-standing cough presented by the 8 
patients with the hypertrophic form of the disease. The agents considered to be responsible for that chronic cough were next analysed, and their relative frequency and importance are presented in Table IV.

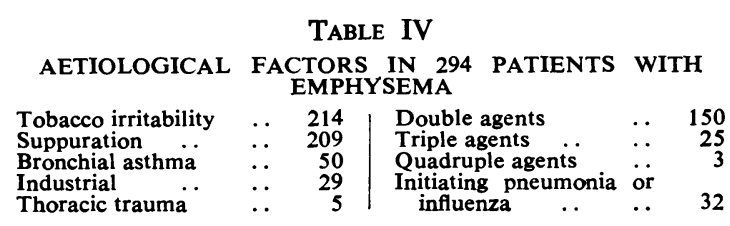

We reviewed the patients suffering from primarily bullous emphysema and tried to correlate the possible aetiological factors in their past histories relative to the production of the disease. It is common to discover a major area of bullous emphysema in an asymptomatic individual. It is also our experience to note a greater tendency for a short episode of antecedent jllness such as chest trauma or pneumonia as possible aetiological agent in bullous emphysema. This is in contradistinction to more protracted illness such as "chronic bronchitis," which is presented in the history of patients with the hypertrophic type of the disease.

In view of the prevalent interest in a possible correlation between the use of tobacco and chronic pulmonary disease, this factor was also analysed. Table $\mathrm{V}$ is an analysis of the smoking habits

TABLE V

ANALYSIS OF SMOKING HABITS OF 250 CASES OF PULMONARY EMPHYSEMA

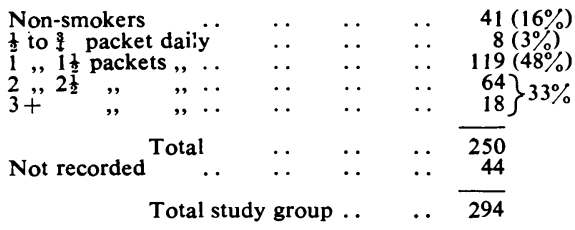

Daily use of cigarettes in terms of packets (20 cigarettes) for from five to 40 years is noted. The majority of 41 non-smokers were women suffering from protracted bronchial asthma.

of the patients studied. It should be noted in considering this study that in many of the patients who did not smoke more than one packet of cigarettes a day smoking had a tendency to produce a chronic cough and wheezing. In a large number of instances, patients who succeeded in stopping the smoking habit obtained complete subjective relief from cough and wheeze, and frequently wheezing was decreased or cured. This factor suggests that not only can the excessive use of tobacco aggravate or even help to produce the disease in the majority of individuals, but there must be a very large number of people in whom bronchial irritation and irritability can be produced by small amounts of tobacco.

Analyses have been made of the evidence of bronchospasm. A patient was considered to have definite evidence of bronchospasm if there was (1) a definite subjective history of wheeze; (2) a wheeze on auscultation of the lungs; (3) a subjective or objective response to bronchodilating drugs; and (4) evidence of spasm at the time of bronchoscopy. The findings relative to this study are drawn up in Table VI. A graphic demonstration of the

TABLE VI

EVIDENCE OF BRONCHOSPASM IN 294 PATIENTS WITH EMPHYSEMA

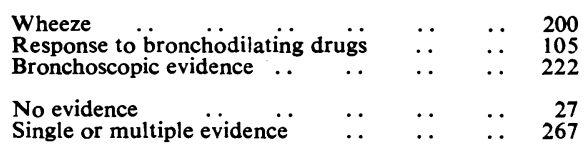

factor of bronchospasm in patients suffering from pulmonary emphysema was obtained by a study of the effects of different drugs upon the maximum breathing capacity. An adequate study of the effect of adrenaline, aminophylline, and banthine bromide was carried out, while a relatively smaller number of patients were investigated in regard to other drugs such as "isuprel," "pronestyl," and "demerol." The results of these studies are shown in Figs. 1, 2, and 3. In a review of the data obtained it was seen that minimal to no effect from bronchodilating drugs occurred in the far-advanced or "fixed" cases of pulmonary emphysema and was particularly liable to occur in the senile group. From a review of the above data the factors of chronic bronchial irritation and of bronchial irritability appear to be definite antecedents and probable aetiological factors in the production of the disease.

Our idea of the mechanism of the production of the hypertrophic form of the disease is as follows. There must be a definite interdependence and interregulation between different circulations, particularly in the same organic system. We know that there are two major flows or circulations through the lung, that of blood and that of air. The interaction of these flows is under the control of the autonomic nervous system. There is a basic similarity in the vascular circulations whether systemic or pulmonary. The acute occlusion of a deep femoral vein produces various degrees of spasm of the femoral artery, often sufficient to make the differential diagnosis between acute arterial and acute venous occlusion difficult. What happens to this physiological rule of circulation in a structure with two or more interdependent circulations? In the recent experimental work of Hanlon, Sabiston, and Burke (1952) 


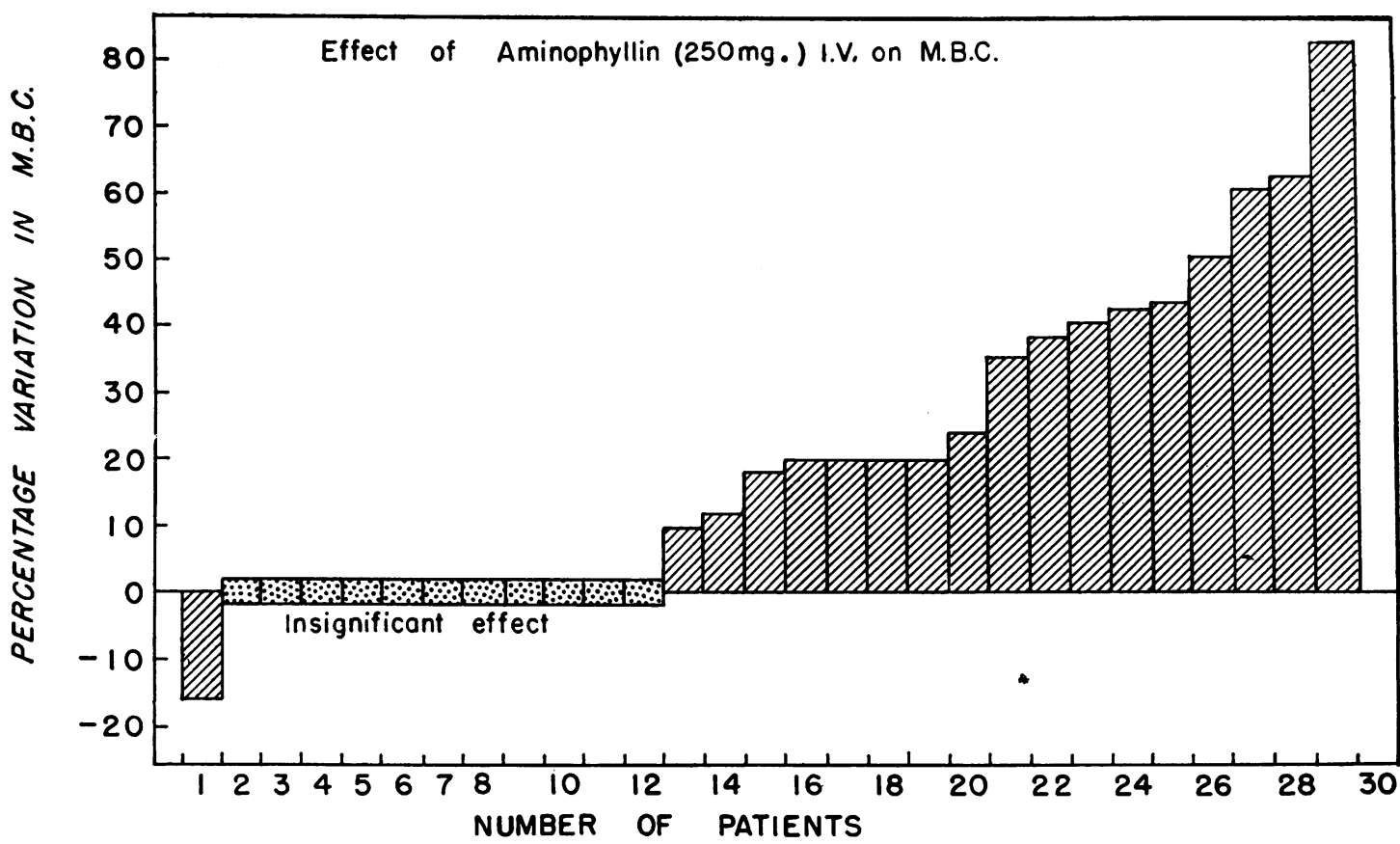

FIG. 1

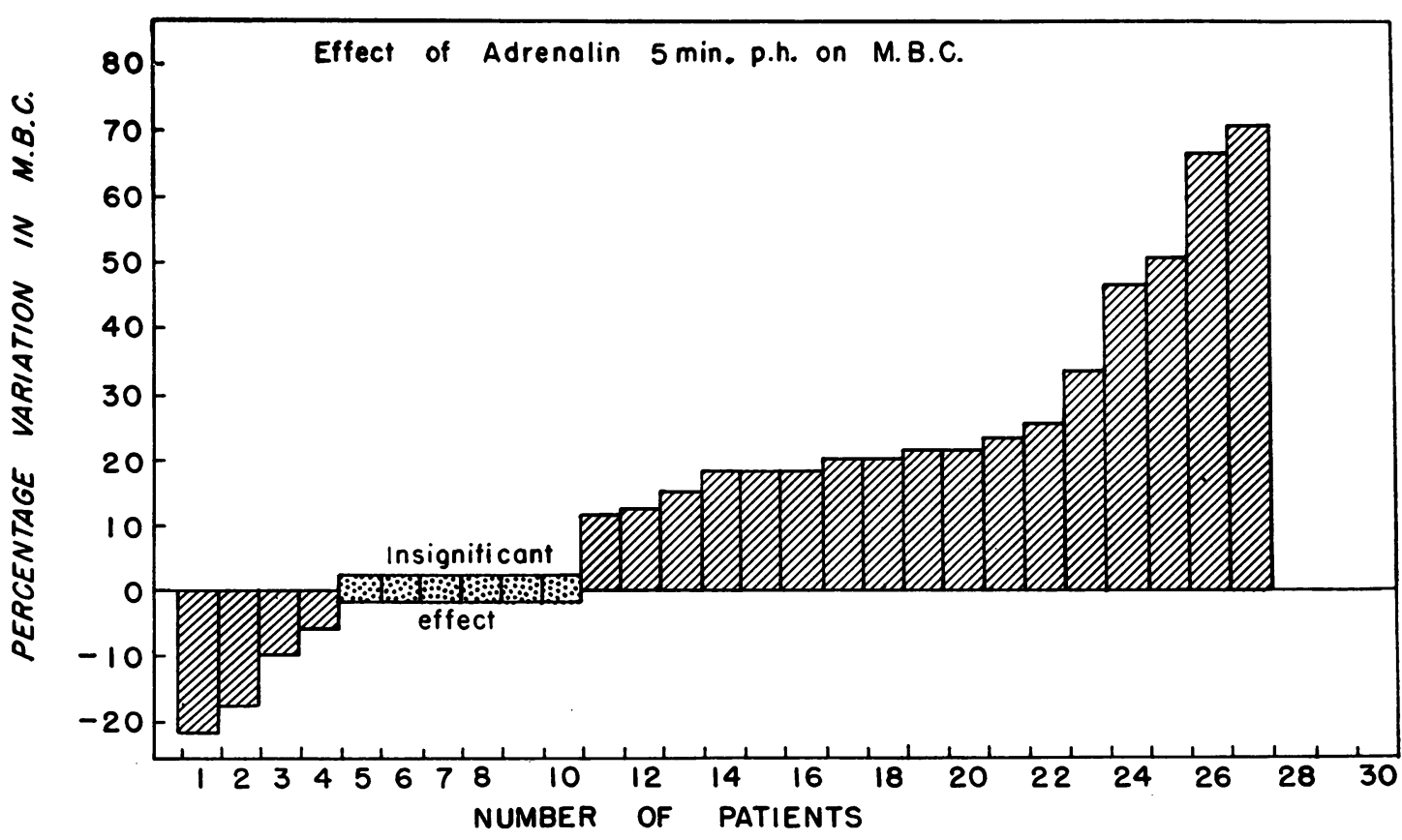

FIG. 2 


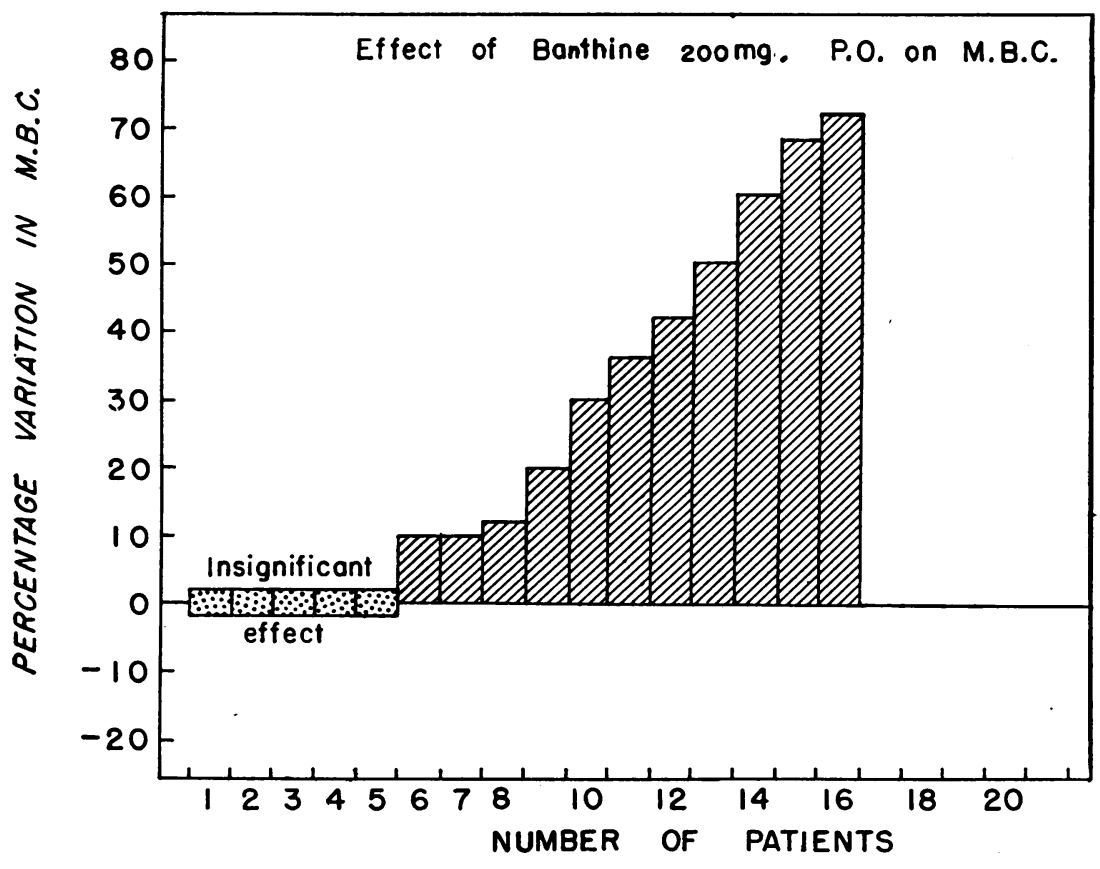

Fig. 3
" progressive obstructive pulmonary atrophy" is preferable to the term "pulmonary emphysema."

We have been interested in studying serial radiographs of patients suffering from the hypertrophic type of pulmonary emphysema. Examination of the earlier films of these patients, and a study of patients with less advanced disease, impresses us with the frequency with which the disease originated in a localized form. It is not uncommon to find the disease predominantly in one or both lower lobes and causing compression of adjacent lung tissue. The absence of the blood vessels of it was shown that the occlusion of a major pulmonary vein experimentally in a dog produces a marked spasm in the pulmonary arteries. A similar angiographic appearance in the dog's lung was produced by Peters and Roos (1952) when a bronchus was occluded. Furthermore, we know that the obstruction of a bronchus increases intra-alveolar pressure and must compress the vascular elements in the alveolar wall. We have reason to presume that bronchial obstruction can act both by direct compression of vascular elements and by reflex methods so as to produce a decreased lumen of the arteries of the lung. We submit therefore that partial or complete obstruction of one of an interdependent pair of circulations in a single organ results in a decreased flow in the other circulation. A specific corollary of this rule in regard to the pulmonary system is that in the lung decreased arterial blood-flow is produced in response to bronchial obstruction, both mechanically by means of direct intra-alveolar pressure upon the vessels within the alveolar walls, and reflexly through the autonomic nervous system. Continued partial or intermittent complete obstruction of a part or all of the bronchial tree not only produces over-distension of the alveoli, but a decrease in arterial blood-flow leads to atrophy of lung tissue. This, it appears, is the mechanism responsible for the atrophic character of pulmonary emphysema. We suggest that the involved areas is in marked contrast to the other parts of the lung (Fig. 4). It is not difficult to presume that these local areas of increased intraalveolar hypertension aid in the overall progress of the disease. We have been impressed with this possibility both upon the radiological examinations of such patients (Fig. 5) and upon the appearances of the lung when the pleural cavity has been opened at operation. This local character of the disease

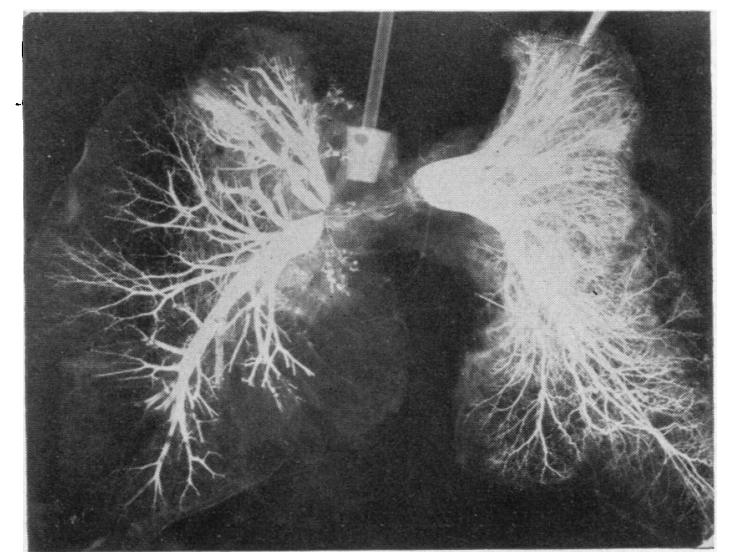

FIG. 4.-Post-mortem specimen of a pair of human lungs with pulmonary arteries filled with lipiodol. Note absence of smalle arteries in the more emphysematous areas (right middle and lower lobes, to lesser extent in left lower lobe). 
seems important, and a better understanding of it should lead to earlier diagnosis of the illness and to a greater therapeutic efficiency. We believe that the initial local areas of emphysema can aid in the progress of the disease by compression upon the veins and bronchi and adjacent lung tissue, and by their action serve as local " trigger areas" capable of producing arterial and bronchial spasm throughout the involved organ system. There is no question about the ability of an area of bronchial ulceration, particularly one occurring in a bronchial stump about a suture following lobectomy, to produce a diffuse bronchospastic syndrome with cough and attacks like asthma. We have often noted the ability of foci of bronchiectasis to produce diffuse bronchial spasticity. Similarly, we have seen the same possibilities in focal areas of emphysema.

To summarize, the aetiology of emphysema constitutes a combination of continued bronchial irritation and bronchial irritability such as to produce a continued partial and intermittent obstruction of the bronchial tree. The resultant alveolar overdistension with compression of the nutrient blood-flow and reflex arterial spasm produces areas of focal atrophy with hyperdistension and destruction of alveoli, namely, localized areas of emphysema, and the two processes combine in the progress of the disease.

\section{Suggested New Classification for Pulmonary EMPHYSEMA}

We have subdivided pulmonary emphysema into three specific types. Type $I$ is symptomatic disease without permanent organic change. Type II is disease which is still localized in relation to permanent organic change. Type III includes the patients with generalized disease and is subdivided into three subgroups according to the persistence of localized intensity of disease. Classification is further subdivided according to whether the lesion is purely bullous, mixed bullous and hypertrophic, or predominantly hypertrophic.

The details of our series of patients have impressed us with the role of a long-standing antecedient cough, wheezing, and dyspnoea before the diagnosis of pulmonary emphysema was made. We , have encountered many patients who have a form of "chronic bronchitis" comparable to that described by the pulmonary emphysema group. These patients gave a history of one to several years of prolonged cough, frequently paroxysmal. There was a subjective and objective manifestation of bronchial wheezing or spasticity. Progressive dyspnoea was a constant part of the disease. These patients on examination showed a prolonged expiratory phase of respiration, but fluoroscopic examination showed no localized obstructive em- 음 physema. The diaphragmatic function was good bilaterally. There was a slight, generalized delay $\frac{\omega}{\vec{D}}$ in the evacuation of air from both lungs as seen $\stackrel{\mathbb{\Omega}}{\Omega}$ fluoroscopically. We consider that this is the first $\stackrel{\infty}{\infty}$ stage of pulmonary emphysema. It represents a $\vec{P}$ physiological obstruction with absent or minimal permanent organic changes, and is a syndrome which, with proper treatment, can be controlled, and by this means later stages of emphysema have $\vec{x}$ been prevented in such patients. We have classified 0 this group as Type I of pulmonary emphysema.

We have been increasingly impressed with the $\overrightarrow{\vec{\sigma}}$ frequency with which pulmonary emphysema may have a solitary localized aspect such that on radioscopy and fluoroscopic examination distinct areas of regional obstructive emphysema are seen on only one side of the thorax. The major symptomatology at this stage is cough and wheeze and $\mathscr{E}$ the degree of dyspnoea may be mild to moderate. This emphasizes the factor of the amount of reserve in the pulmonary apparatus, and the need to study patients for possible pulmonary emphysema before the advent of marked dyspnoea. These cases constitute Type II.

When the disease becomes generalized in regard to permanent organic change we consider the $\frac{0}{3}$ patient to be classified in Type III. This type is then subdivided into three subgroups, A, B, and $\mathrm{C}$, according to the severity of the illness. Type IIIC consists of those patients in whom so-called fixed universal emphysema is present. Fluoroscopic $\underset{\sim}{\stackrel{D}{x}}$ examination in such a group reveals extremely $\dot{0}$ minimal, if any, movement of the diaphragm. The maximum breathing capacity would be 30 litres $\delta$ per minute or below. There is minimal, if any, $₹$ change in the maximum breathing capacity upon 은 administration of bronchodilating drugs.

\section{Special Diagnostic Considerations}

In studying a fairly large group of patients $N$ suffering from pulmonary emphysema certain special diagnostic aids have been particularly useful, $\omega$ and these should be mentioned briefly.

FluOROSCOPY.-Fluoroscopic examination is the most important tool for the proper evaluation and $\stackrel{\mathcal{f}}{+}$ early diagnosis of pulmonary emphysema. The 0 total excursion of each diaphragm is carefully noted; any lag in the descent of one diaphragm or $\stackrel{\mathbb{\Omega}}{\stackrel{\oplus}{\circ}}$ the other is noted. Not uncommonly both dia- $\frac{\mathbb{Q}}{2}$ phragms may tend to descend to their full excursion 0 together, but on one side the overlying lung tissue 
cannot fill as quickly as its counterpart, therefore the diaphragm on the involved side " jumps back" through a short excursion and then redescends as the overlying lung tissue fills adequately. The same phenomenon may be noted in reverse during the expiratory phase, and we have termed this behaviour " diaphragmatic jump-back pattern." It is a sign indicative of either unilateral emphysematous involvement or an increased degree of involvement on one side. In severe instances of localized intraalveolar pulmonary hypertension due to obstructive emphysema the diaphragm on the involved side may be delayed in its ascent during expiration or actually be forced to increase its descent during the expiratory phase. We have coined the term " pseudo-paradoxical " movement of the diaphragm for this phenomenon.

Any tendency for unusual displacement of the heart or mediastinum during the act of expiration is noted, as this may be a sign of increased intraalveolar hypertension localized to one side of the thorax. The barium-filled oesophagus is also studied, and, on occasion, a mediastinal pulmonary hernia may be discovered. The ability of each lung to expel air, both in regard to rapidity and uniformity, is noted. Localized high-lights and non-opacification are noted and are interpreted as areas of localized emphysema. The vascular pattern of the two lungs is carefully noted both as to its presence and its mobility and ability to fill on coughing. Absence of the finer radicals of the blood vessels or splinting of the structures is interpreted as emphysema in this area. We have used the fluoroscope also as an aid in the postoperative study of patients suffering from emphysema. We have been impressed with the more rapid and complete opacification of the lung on the side which has been denervated and with the increased mobility of the diaphragm and shifting of the mediastinal contents toward the side of operation at the completion of forced expiration.

ANGIOCARDIOGRAPHY.-We have also utilized angiocardiographic mapping of the pulmonary vascular system as an aid in the localization of areas of pulmonary emphysema and as a part of the post-operative evaluation. Figs. $5 a$ and $5 b$ show a pre- and post-operative angiocardiographic study. This patient had mixed hypertrophic and bullous emphysema with increased intra-alveolar pulmonary hypertension noted clinically and fluoroscopically over the right upper lung field. The
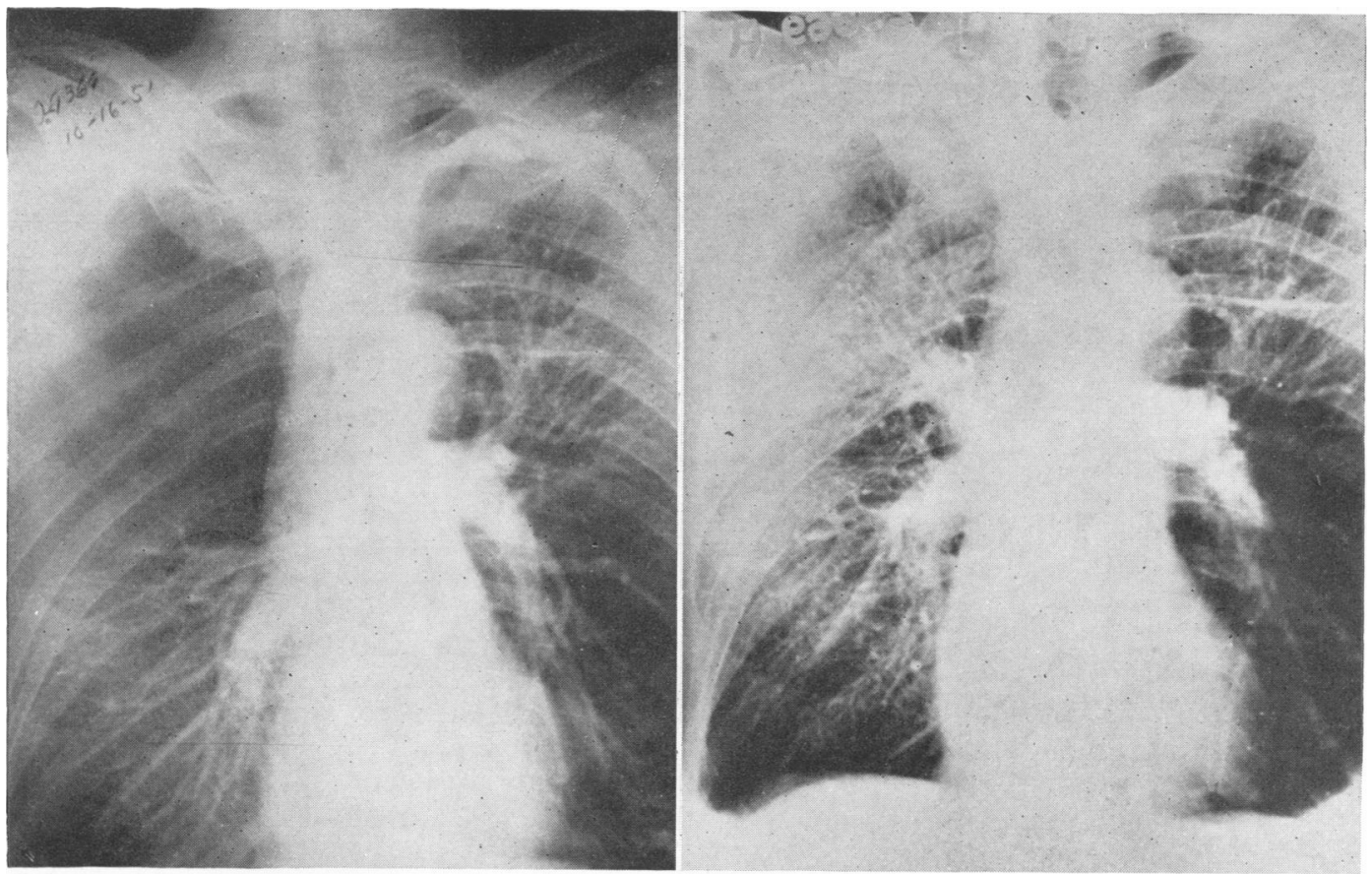

FIGS. $5 a$ and $5 b$.-Diodrast radiographs of lungs of patient suffering from pulmonary emphysema before and after surgical excision of major bulla compressing right upper lung field. Pulmonary arterial trunk to right upper lobe almost non-opacified in Fig. $5 a$, while lower and middle lobe trunk is depressed and spastic. Fig. $5 b$ shows the state of the arteries after excision of bulla and complete plexectomy. Left lower lobe is the site of advanced hypertrophic emphysema. Moderate hypertrophic disease was 
absence of the blood vessels of the lung in this region and the downward depression of the vascular component of adjacent lung tissues confirm the clinical impression. Evidence of a hypertrophic type of pulmonary emphysema over the left lower lobe can also be seen in these films. However, there is no evidence of compression of adjacent pulmonary vascular structures to the degree noted on the right. We were able accurately to predict improvement from surgical measures carried out on the right side.

\section{TheraPeUtic Considerations AND EXPERIENCES}

In the past treatment for pulmonary emphysema has been directed towards the control of individual symptoms or individual factors involved in the disease. Bronchodilating drugs of various types have been used probably more frequently than any other single method of treatment. Interest in diaphragmatic activity brought trials of pneumoperitoneum as long as 40 years ago, and it has enjoyed varying degrees of popularity. In similar fashion, abdominal supports or so-called " emphysema belts" have been used. Greater attention has been given during the past decade to remedial respiratory exercises. Bronchoscopy has been utilized in conjunction with bronchial lavage, particularly in those patients who have a major degree of suppuration. In 1923 Kümmell stated that there was improvement in the emphysematous factor of patients with bronchial asthma on whom dorsal sympathectomy was carried out. Emphysematous bullae have been excised for the past 20 years. In 1950 we (Abbott, Hopkins, and Giulfoil) reported the combined use of resection of hypertrophic as well as bullous emphysematous tissue together with various pulmonary denervation procedures. In 1952 Crenshaw and Rowles reported a group of patients in whom they had added the procedure of excision of the parietal pleura and poudrage to our procedure of pulmonary denervation and tissue resection. Neither Crenshaw nor ourselves have confined surgical therapy to patients suffering from the bullous type of the disease, but have carried out various surgical procedures upon the mixed bullous and hypertrophic and upon the pure hypertrophic types of emphysema.

\section{Rationale for OUR THerapeutic APProach}

There is no question but that the anxiety which is commonly associated with pulmonary emphysema can, and does, aggravate the severity of the patient's incapacity. We are also impressed with the number of patients in whom complete separation from tobacco decreases the degree of spasm of the bronchial tree and bronchial irritation so that clinical benefit is obtained from this alone. Some improve- $\bar{C}$ ment can be derived from treatment of the sup- $\frac{\bar{\sigma}}{\bar{\sigma}}$ purative factor of the disease by multiple bron- $\frac{\bar{D}}{\bar{Q}}$ choscopic procedures, proper chest exercises, expec- $\stackrel{\mathbb{}}{\varrho}$ torants, and chemotherapy. Treating any of these three factors does not improve the patient's $\vec{\circ}$ emphysema, but eradicates accessory components so that the patient obtains the maximal use of the $\vec{\omega}$ pulmonary tissue which remains. In all patients involved in this study a preliminary regime directed $\vec{x}$ towards improvement of the respiratory muscula- $\infty$ ture, eradication of extrinsic irritants, such as? tobacco, and intrinsic irritants, such as infection, $\overrightarrow{\vec{\sigma}}$ and major reassurance was carried out. They 0 were also given that bronchial dilating drug which appeared to be most efficient in the individual $\vec{c}$ case. Patients were treated in this way for at least four to six months before carrying out any major ${ }^{\Phi}$ operation. This gave us a satisfactory basis on $\vec{G}$ which to evaluate the operative procedures. It also $\omega$ allowed us to estimate how much benefit could be obtained from a so-called "conservative" or non-operative approach, and which patients could expect benefits from such management. A study

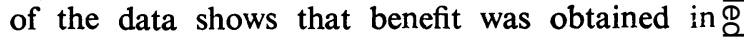
those patients in whom a lot of suppuration was $\overrightarrow{\vec{A}}$ present, and in those in whom tobacco was appar- $\frac{0}{3}$ ently playing a major role in the bronchial irritability and bronchial spasm. The results of this study are presented in Table VII.

TABLE VII

\begin{tabular}{|c|c|c|c|c|}
\hline \multirow{2}{*}{$\begin{array}{c}\text { Degree of } \\
\text { Suppuration }\end{array}$} & \multirow{3}{*}{$\begin{array}{c}\begin{array}{c}\text { No. } \\
\text { of } \\
\text { Cases }\end{array} \\
42^{*} \\
91 \\
56\end{array}$} & \multicolumn{3}{|c|}{ Results } \\
\hline & & Good & Fair & Poor \\
\hline $\begin{array}{ll}\begin{array}{l}\text { None } \\
\text { Moderate } \\
\text { Severe }\end{array} & \ldots \\
\end{array}$ & & $\begin{array}{r}9 \\
29 \\
29\end{array}$ & $\begin{array}{r}8 \\
44 \\
19\end{array}$ & $\begin{array}{c}25+ \\
18 \\
8\end{array}$ \\
\hline Total & 189 & 67 & 71 & 51 \\
\hline
\end{tabular}

The conservative regime, therefore, was used at first upon patients with all grades of emphysema In Type I, where no permanent organic damage had occurred and the disability could be reversed by this regimen, this treatment was used alone 0 (Table VIII). In patients who had the Type IIO

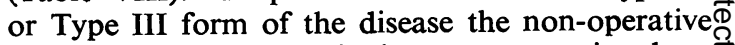
regime was used to obtain a comparative base $\frac{\overrightarrow{0}}{0}$ line for the study of the therapeutic efficiency of $\sigma$ the operative approach, to define the need for more 
TABLE VIII

EFFECT OF CONSERVATIVE REGIME UPON 17 CASES OF TYPE I EMPHYSEMA

\begin{tabular}{|c|c|c|c|c|c|}
\hline \multirow{2}{*}{\multicolumn{2}{|c|}{$\begin{array}{c}\text { Degree of } \\
\text { Suppuration }\end{array}$}} & \multirow{2}{*}{$\begin{array}{l}\text { No. } \\
\text { of } \\
\text { Cases }\end{array}$} & \multicolumn{3}{|c|}{ Results } \\
\hline & & & Good & Fair & Poor \\
\hline $\begin{array}{ll}\text { None } & \ldots \\
\text { Moderate } & \ldots \\
\text { Severe } & \ldots\end{array}$ & $\begin{array}{l}. \\
\because .\end{array}$ & $\begin{array}{r}3 \\
13 \\
1\end{array}$ & $\begin{array}{r}2 \\
12 \\
1\end{array}$ & 1 & 1 \\
\hline Total & .. & 17 & 15 & 1 & 1 \\
\hline
\end{tabular}

aggressive therapy, and to get the patient in the best condition for major surgical intervention. In the early part of the study some patients were treated by dorsal sympathectomy or vagotomy alone. We have to come to the conclusion that sympathectomy or vagotomy alone is rarely a valuable procedure in patients with pulmonary emphysema. The remaining patients, therefore, who were operated upon were treated by a combined denervation procedure, removing both the sympathetic and parasympathetic system with tissue resection as a rule.

\section{Specific Surgical Considerations}

If unilateral surgery was done the stellate ganglion and the upper six dorsal ganglia were removed. If bilateral surgery was carried out the stellate ganglion on the second side was preserved, but the remainder of the upper six dorsal ganglia were excised. In operations carried out upon the right side of the thorax the vagus nerve was transected in its entirety just distal to the right recurrent laryngeal nerve. On the left side parasympathectomy was considerably different, because it was felt important to maintain the integrity of the left vagus nerve to the gastro-intestinal tract. Therefore all the vagus fibres were transected in the hilus of the lung, according to the techniques described by Blades, Feattie, and Elias (1950) and ourselves (1952). This is defined as "complete pulmonary plexectomy." Excision of the adventitia of the main pulmonary artery on the side involved was also carried out to complete the removal of the sympathetic components to the pulmonary arterial system. If the patient had localized bullae, then these were excised. If the major areas of hypertrophic emphysema were confined to one lobe, then the entire lobe was removed if it was felt safe to sacrifice it without causing too much over-stretching of the remaining lung tissue. In many instances, where the hypertrophic disease was diffuse, only the basilar segments of the lower lobe were removed.

It was not possible to carry out a true segmental resection, so we had to devise a modification of this procedure. A large raw surface of lung tissue in these patients produces permanent fistulae. Therefore we sacrificed the nutrient pulmonary arteries to the segments to be excised, ligated major trunks of the veins of the involved segments, and then transected the tissue between clamps. Our early experience showed that any extensive suture line in lung tissue of this type was conducive to the production of extensive blood extravasation throughout emphysematous lung tissue, as well as to produce a greater frequency of fistula formation. We therefore devised a method of resection utilizing the coarctation clamps devised by Willis Potts. With these clamps (Fig. 6), the suturing is carried out through an area of lung made ischaemic by the clamps without damaging the tissue. A series of interrupted fine silk sutures is placed distal to the clamp. Then a running suture of fine chromic catgut on an atraumatic needle is used, running first as a continuous mattress suture and coming back as an over-and-over suture, similar to that used by Potts in the closure of the stumps of a patent ductus arteriosus. The amount of hypertrophic tissue excised in these patients was judged primarily by the amount which could be sacrificed without leaving too large a dead space. Dead space was filled by elevating the diaphragm, and this was done by inducing a pneumoperitoneum through a small opening in the diaphragm at the time of the lung resection.

In some patients the disease was so uniform and diffuse that no excision was utilized. This group consisted of those patients who had marked pulmonary fibrosis, and the diaphragm was not markedly displaced downwards. In this group pure denervation was used, and more recently the

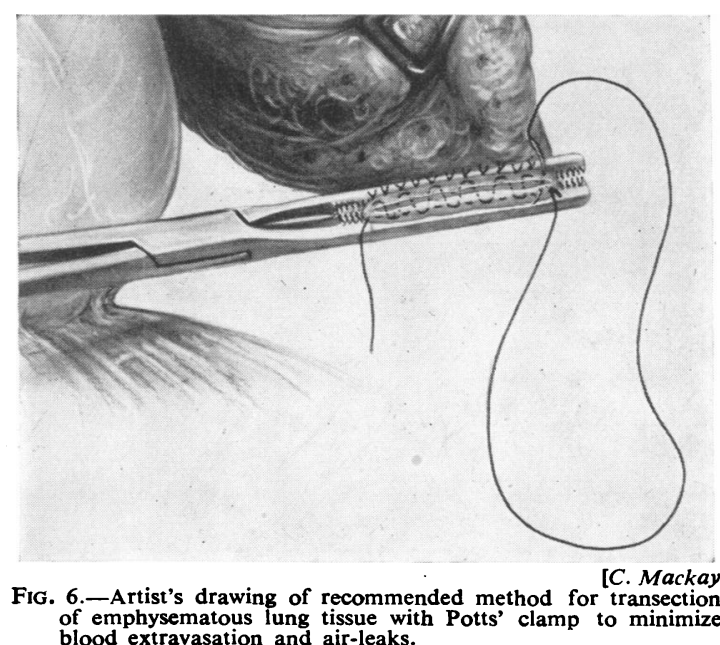


addition of excision of the parietal pleura with some poudrage has been added. Since the report of Crenshaw and Rowles (1952) we have added this procedure to many of the emphysema surgical operations, and plan a comparative study to define the need for this addition. Perhaps it may help by providing additional support to an inelastic lung as well as by promoting development of a collateral circulation.

\section{SURGICAL EXPERIENCES}

In 1947 we began combining denervation procedures with tissue excision. There had been considerable discussion in regard to the efficacy of the treatment of bullous emphysema by surgical excision of the bullae. Several authors dampened an initial enthusiasm for the procedure by describing a subsequent progressive character to the underlying emphysema and ultimately death from pulmonary insufficiency, so we thought that local excision of a bulla or bullae alone might be a disappointing procedure because it constituted an incomplete operation. We therefore made a point of eradicating other sources of bronchopulmonary irritation besides the bulla, such as tobacco or infection, and added denervation surgery to decrease bronchial irritability and improve pulmonary circulation. The results of such an attack on 10 patients who had massive bullae, and on 11 who had a combination of bullae and a severe degree of hypertrophic emphysema, are outlined in Table IX.

TABLE IX !

RESULTS OF SURGICAL TREATMENT OF BULLOUS AND MIXED TYPE EMPHYSEMA

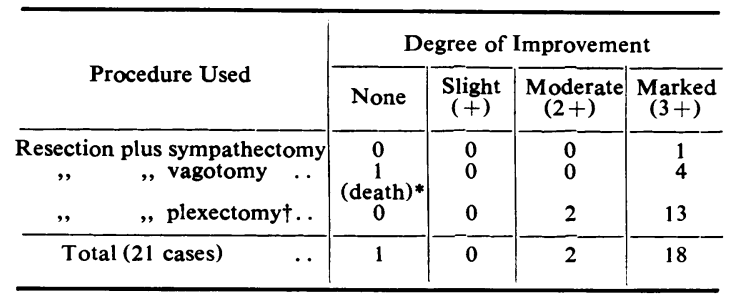

* Death due to digitalis intoxication

$\dagger$ Includes patients with major amounts of bilateral hypertrophic disease.

Except for one fatal case due to a preventable catastrophe, the clinical benefits have been striking. Follow-up studies three to five years after surgery have shown continued good health without progress of the pulmonary emphysema.

At the outset our surgical measures for the hypertrophic type of emphysema were confined to surgery of the autonomic nervous system. Following the report of Carr and Chandler (1948) upon the $\overrightarrow{\bar{s}}$ efficacy of sympathectomy for bronchial asthma, weo attempted to apply this to a few severely debilitatedo pulmonary emphysema cases in which there was a $\frac{\bar{m}}{5}$ major degree of associated bronchospasm. In all

TABLE $X$

RESULTS OF DIFFERENT TYPES OF DENERVATION ALONE UPON DIFFUSE HYPERTROPHIC PULMONARY EMPHYSEMA (TYPE IIIB AND IIIC)

\begin{tabular}{|c|c|c|c|c|c|}
\hline \multirow{2}{*}{ Procedure } & \multirow{2}{*}{$\begin{array}{l}\text { No. } \\
\text { of } \\
\text { Cases }\end{array}$} & \multicolumn{4}{|c|}{ Degree of Improvement } \\
\hline & & None & $\begin{array}{c}\text { Slight } \\
(+)\end{array}$ & $\begin{array}{c}\text { Moderate } \\
(2+)\end{array}$ & $\begin{array}{c}\text { Marked } \\
(3+)\end{array}$ \\
\hline $\begin{array}{c}\text { Sympathectomy: } \\
\text { Unilateral .. } \\
\text { Bilateral .. }\end{array}$ & $\begin{array}{l}3 \\
3\end{array}$ & $\begin{array}{l}3 \\
3\end{array}$ & $\begin{array}{l}0 \\
0\end{array}$ & $\begin{array}{l}0 \\
0\end{array}$ & $\begin{array}{l}0 \\
0\end{array}$ \\
\hline Total & 6 & 6 & 0 & 0 & 0 \\
\hline $\begin{array}{l}\text { Vagotomy: } \\
\text { Unilateral .. } \\
\text { Bilateral } \ldots\end{array}$ & $\begin{array}{l}2 \\
1\end{array}$ & $\begin{array}{l}2 \\
1\end{array}$ & $\begin{array}{l}0 \\
0\end{array}$ & $\begin{array}{l}0 \\
0\end{array}$ & $\begin{array}{l}0 \\
0\end{array}$ \\
\hline Total & 3 & 3 & 0 & 0 & 0 \\
\hline $\begin{array}{c}\text { Plexectomy (alone): } \\
\text { Unilateral .. } \\
\text { Bilateral } \ldots\end{array}$ & $\begin{array}{l}6 \\
3 \\
\end{array}$ & $\begin{array}{l}1 \\
1\end{array}$ & $\begin{array}{l}0 \\
0\end{array}$ & $\begin{array}{l}1 \\
1\end{array}$ & $\begin{array}{l}4^{*} \\
1\end{array}$ \\
\hline Total & 9 & 2 & 0 & 2 & 5 \\
\hline
\end{tabular}

* All of these four belong to non-distended group with majo? fibrosis.

(Table $\mathrm{X}$ ) six patients were operated upon utilizing an extrapleural approach, three undergoing uni lateral and three having bilateral upper dorsa? sympathectomies, excising from the stellate ganglion down through the sixth dorsal ganglion. $\mathrm{N}$ demonstrable benefit, either subjective or objectiven was obtained in this group.

The next approach consisted of transection o the vagus nerve, either as a high right vagus nerve section or by transecting the vagus nerve branches to the lung on the left side. Two unilateral right vagotomies and one bilateral operation were carried out. These three patients all had severes bronchial asthma as well as advanced pulmonary emphysema. Transient benefit to the asthma wass noted, but no useful long-term results were accom $N$ plished. These three patients had either universañ bronchial suppuration or narcotic addiction. Such patients, we now know, are not benefited by an known surgical or medical approach to their intractable asthma. We cannot consider this small group as a result contradicting the possible value of vagotomy alone in emphysema.

The ability of such severely debilitated patient to tolerate major transpleural surgery encourage us to try more extensive procedures. We began inf 1948 to combine excision of hypertrophic emphys sematous tissue with various forms of autonomie 
nerve surgery. In some instances, where the disease was uniform and universal and major objective benefits could be obtained from bronchodilating drugs, we still carried out autonomic nerve surgery alone but also as a combined procedure in the form of a " complete pulmonary plexectomy " (upper dorsal sympathectomy, periarterial sympathectomy of the pulmonary artery, and vagotomy). Nine patients fell in this group. Six underwent unilateral and three had bilateral surgical procedures. No improvement was obtained in two patients, moderate improvement in two patients, and dramatic improvement was produced in five patients. Study of this group revealed that four of the five obtaining marked improvement had a lot of associated pulmonary fibrosis (see subsequent detailed case reports). In these patients major depression of the diaphragm was not present; fair mobility, in fact, persisted. There was in each instance a severe delay in expiration, the maximum breathing capacity being between 35 and 44 litres per minute, and large primary pulmonary arteries and a visibly severely damaged lung were noted at the time of surgery. One of these patients has now been followed up for more than three years since her operation and continues to improve. This appears to constitute a rare but important group, and one wonders whether an associated primary arteritis might be involved. We have been interested to note that Crenshaw and Rowles (1952) have also been impressed with the benefits obtainable in this group, which they refer to as " the cotton candy lung."

The treatment of patients who have the hypertrophic type of emphysema by combined extirpation and neurectomy was a natural consequence upon the encouraging results obtained in the bullous and mixed groups. It was presumed from the outset that some patients would be treated in whom the disease was too extensive for real help or palliation. However, experimental clinical surgery demands that the so-called "hopeless" cases be attempted first. Ten such patients have been treated (Table XI). No major benefit was obtained in this group. Three deaths occurred due to the method of pulmonary suture used which produced considerable blood extravasion and haemorrhagic pneumonitis, and lack of the knowledge in the early stages of this work that all patients with denervated bronchi must receive almost daily bronchoscopy in the early post-operative period.

In patients with the diffuse hypertrophic type of pulmonary emphysema who still had some focal character of the disease or areas of demonstrably greater increased intra-alveolar pressure, the results of surgical measures were markedly different.
TABLE XI

ANALYSIS OF SURGICAL TREATMENT OF DIFFUSE HYPERTROPHIC PULMONARY EMPHYSEMA BY TISSUE RESECTION AND DENERVATION

\begin{tabular}{|c|c|c|c|c|c|c|}
\hline \multirow[b]{2}{*}{ Type } & \multirow{2}{*}{$\begin{array}{l}\text { Procedure } \\
\text { Used }\end{array}$} & \multirow{2}{*}{$\begin{array}{c}\text { No. } \\
\text { of } \\
\text { Cases }\end{array}$} & \multicolumn{4}{|c|}{ Degree of Improvement } \\
\hline & & & None & Slight & $\begin{array}{l}\text { Mod- } \\
\text { erate }\end{array}$ & Marked \\
\hline IIIA & $\begin{array}{l}\text { Resection plus vago- } \\
\text { tomy } \\
\text { Resection plus plexec- } \\
\text { tomy } \quad . .\end{array}$ & $\begin{array}{r}1 \\
13\end{array}$ & 0 & 0 & $\begin{array}{l}0 \\
4\end{array}$ & $\begin{array}{l}1 \\
9\end{array}$ \\
\hline & Total & 14 & $\mathbf{0}$ & 0 & 4 & 10 \\
\hline IIIB & $\begin{array}{l}\text { Resection plus vago- } \\
\text { tomy } \\
\text { Resection plus plexec- } \\
\text { tomy } \quad . .\end{array}$ & 3 & 0 & 0 & 2 & 1 \\
\hline & Total & 4 & 0 & 0 & 3 & 1 \\
\hline IIIC & $\begin{array}{l}\text { Resection plus vago- } \\
\text { tomy } \\
\text { Resection plus plexec- } \\
\text { tomy }\end{array}$ & 9 & $\begin{array}{c}8 \\
(3 \\
\text { deaths })\end{array}$ & 0 & 0 & 0 \\
\hline & Total & 10 & 9 & 1 . & $\mathbf{0}$ & $\mathbf{0}$ \\
\hline
\end{tabular}

Thus, a patient with Type IIIA obvious bilateral emphysema, but in whom the mediastinum constantly shifted towards the less distended side on expiration, obtained dramatic benefit. As the disease progressed to major bilateral foci, then the degree of rehabilitation became less marked. We interpret the results of this study to show that surgical procedures can benefit selected patients with the hypertrophic type of pulmonary emphysema, but such benefits decrease as the disease becomes more advanced and uniform, approaching the so-called " fixed" stage.

The results of our overall surgical experience in 67 patients are outlined in Table XII. It should be stressed that in the light of our present knowledge and selection of patients a considerably better percentage of improvements should be obtained in the hypertrophic group. Of the 46 patients in this group, six were treated by sympathectomy alone without benefit, three patients who would now be refused any form of surgery had vagotomy alone, and 10 patients with fixed

\section{TABLE XII}

SUMMARY OF RESULTS OF VARIOUS SURGICAL PROCEDURE USED IN 67 CASES OF PULMONARY EMPHYSEMA

\begin{tabular}{|c|c|c|c|}
\hline Type & $\begin{array}{l}\text { No. of } \\
\text { Cases }\end{array}$ & $\begin{array}{c}\text { Major } \\
\text { Improvement }\end{array}$ & Deaths \\
\hline $\begin{array}{ll}\text { Bullous } & \\
\text { Mixed } & \ldots \\
\text { Hypertrophic } & \ldots\end{array}$ & $\begin{array}{l}10 \\
11 \\
46\end{array}$ & $\begin{array}{l}10 \\
10 \\
25\end{array}$ & $\begin{array}{l}0 \\
1 \\
3\end{array}$ \\
\hline Total ... & 67 & 45 & 4 \\
\hline
\end{tabular}


(IIIC) emphysema were operated upon. If these 19 patients are disregarded, then it might be stated that in 29 properly selected patients with hypertrophic pulmonary emphysema surgical intervention of appropriate type yielded benefits in 25 of the 27 .

\section{ANaesthetic and Post-operative Considerations}

Our anaesthesia experiences must be briefly mentioned. The surgeon must be aware of the possibility of a pneumomediastinum or pneumothorax being produced by straining or paroxysmal cough during induction in this group of patients. The residual air may be increased by positive pressure anaesthesia in the presence of bronchospasm. For these two reasons we take special care to induce anaesthesia slowly and to prevent bronchospasm. Intravenous novocaine, $0.2 \%$, is administered liberally before induction. Aminophylline in doses of $3 \frac{1}{2}$ or $7 \frac{3}{4} \mathrm{gr}$. is given intramuscularly before induction. Following induction the vocal cords and upper trachea are anaesthetized with cocaine before endotracheal intubation. We prefer to avoid positive pressure anaesthesia until the chest is open, since we do not like to increase intraalveolar tension in a closed space in patients with increased pulmonary resistance. In some cases with massive tension bullae the patient may become acutely distressed, requiring immediate opening of the chest and incision of the offending bullae.

Post-operatively the one important rule is frequent bronchoscopy despite apparent negative physical findings. Patients suffering from emphysema have a poorly effective cough under any circumstances, and it is usually totally ineffective for the first five to 10 days after thoracotomy and bronchial denervation. The second important factor is the periodic use of bronchodilators, such as aminophylline or " isuprel," for the first five to seven days to control bronchospasm secondary to the irritative effect of transection upon the distal cut segment of the vagus

TABLE XIII

STATISTICAL DATA FROM REPEATED CARDIAC CATHETERIZATION DEMONSTRATING EFFECT OF COMBINED PULMONARY DENERVATION AND EXCISION OF AREAS OF HYPERTROPHIC EMPHYSEMA

\begin{tabular}{|c|c|c|}
\hline & Pre-operative & $\begin{array}{l}\text { Post-operative } \\
\text { (4 Months) }\end{array}$ \\
\hline 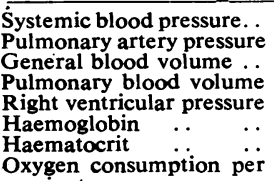 & $\begin{array}{l}113 / 61 \mathrm{~mm} . \mathrm{Hg} \\
31 / 12(20) \mathrm{mm} . \mathrm{Hg} \\
3,975 \mathrm{ml} . / \mathrm{m} .2 \\
874 \mathrm{ml} . / \mathrm{m} .2 \\
26 / 6(13 \cdot 5) \mathrm{mm} . \mathrm{Hg} \\
11 \cdot 1 \mathrm{~g} \cdot / 100 \mathrm{ml} . \\
36 \cdot 7 \%\end{array}$ & $\begin{array}{l}95 / 62 \mathrm{~mm} . \mathrm{Hg} \\
22 / 8(12) \mathrm{mm} . \mathrm{Hg} \\
3,109 \mathrm{ml} . / \mathrm{m} .2 \\
598 \mathrm{ml} . / \mathrm{m} .2 \\
12.2 \mathrm{~g} . / 100 \mathrm{ml} . \\
39.4 \%\end{array}$ \\
\hline minute .. $\quad \ldots \quad \ldots$ & 190 c.c. & 270 c.c. \\
\hline
\end{tabular}

nerve. Finally, the frequency of cardiac arrhythmias and gastric dilatation must be borne in mind.

Table XIII summarizes the results of repeated cardiac catheterization to compare the pre- and post-operative pictures in the series.

\section{Exemplary Case Abstracts}

The following four case abstracts are presented to exemplify the types of patients treated. Some of the objective studies carried out on these patients are described.

The first patient, Mr. H. C. W., exemplifies the situation presented by a major degree of bullous and mixed type emphysema. We were able to $\vec{\sigma}$ obtain radiographic studies over a two-year period o before operation, and these studies portray the progressive character of the disease (Figs. $7 a$ and $b$ ). This patient's record was as follows:

Mr. H. C. W., a 51-year-old white man, a farmer, had a family history of no significance. He had smoked $f$ one packet of cigarettes a day for over 30 years. He had had multiple operations for carcinoma of the lip and nose during the years 1943 to 1946 . In 1947 he began to note a chronic cough, occasionally productive of very sticky material. Dyspnoea on heavy labour was first noted in 1949. Wheezing had been noted since 1949. Disability progressed so that he had to stop work.

Physical examination showed an increased diameter $\overrightarrow{\overrightarrow{0}}$ of the chest, restricted mobility of the chest cage, absent breath sounds over the upper two-thirds of the right lung, and coarse rales over the lower right anterior chest. The breath sounds were locally intensified as if by compression.

Fluoroscopic examination showed large emphysematous blebs occupying most of the right lung field with $:$ compression of the lower and medial components of 3 the pulmonary bed. There appeared to be compression and distortion of the pulmonary vascular bed on the right. The right diaphragm ascended less than $1 \mathrm{~cm}$. on forced expiration, while the left diaphragm ascended $\frac{9}{5}$ approximately $2 \frac{1}{2} \mathrm{~cm}$. Some obstructive emphysema was noted over the left upper thorax on forced expiration.

Objective studies on February 4, 1951, gave: maximum breathing capacity, 51.41 . per min.; walking ventilation, 응 26.8 1. per min.; dyspnoeic index, 0.53 ; breathing $N$ reserve, $48 \%$.

The patient was operated upon, and massive emphy- $\omega$ sematous bullae were removed from the right lung. $A ₹$ considerable amount of associated diffuse hypertrophice emphysema was seen throughout the right pulmonary $\Phi_{\infty}$ tissue. A high right vagus nerve resection as well as? upper dorsal sympathectomy was carried out. The $T^{-}$ remaining lung tissue expanded sufficiently to fill the chest so that no pneumoperitoneum was carried out. The post-operative course was uneventful.

The patient became completely free of cough, and $\varrho$ in March, 1952, fluoroscopic examination revealed that the right diaphragm ascended more than $4 \mathrm{~cm}$. on 


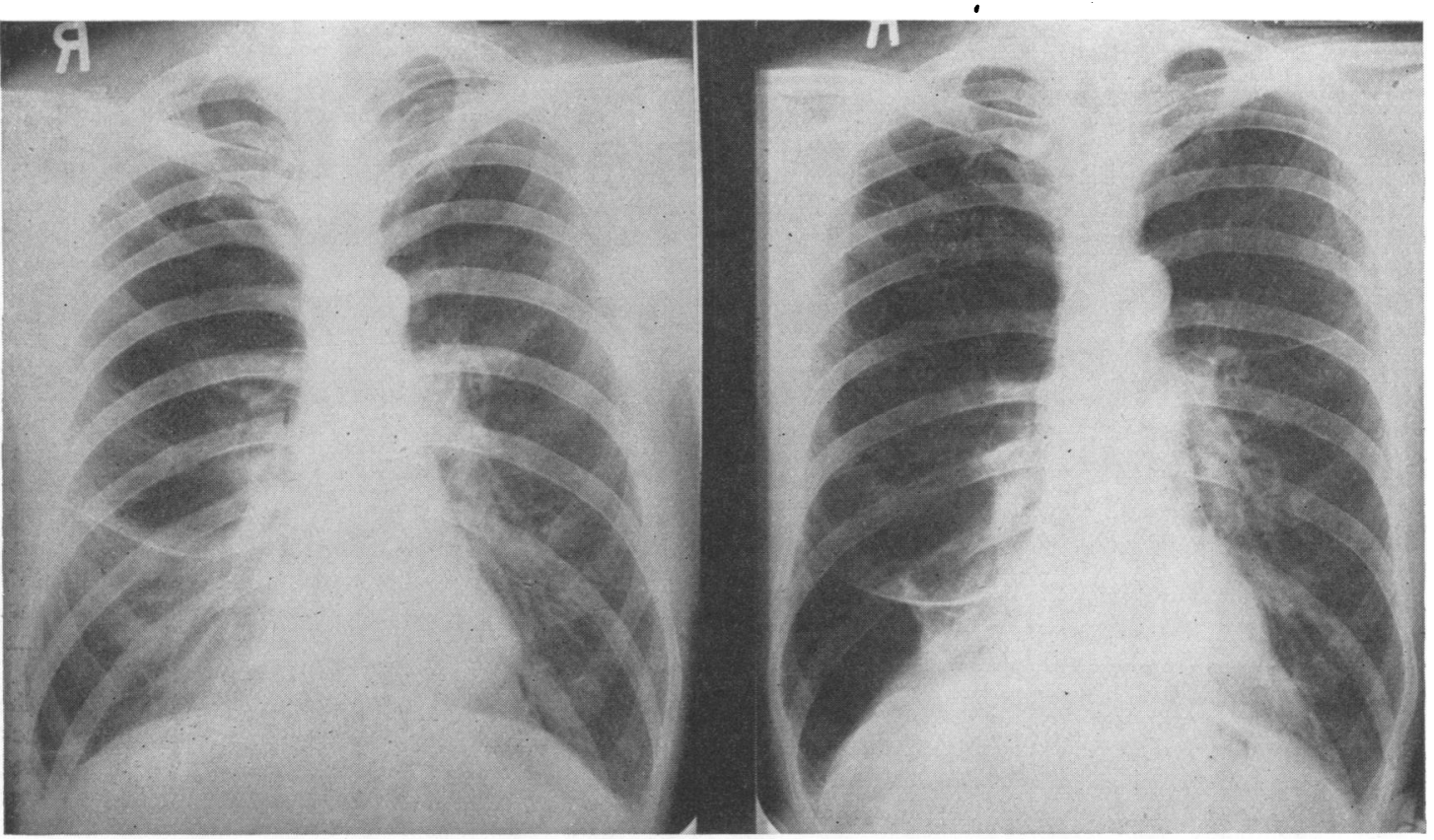

FIGs. $7 a$ and $7 b .-$ Radiographs of H. C. W. taken two years apart showing the progressive character of the lesion.

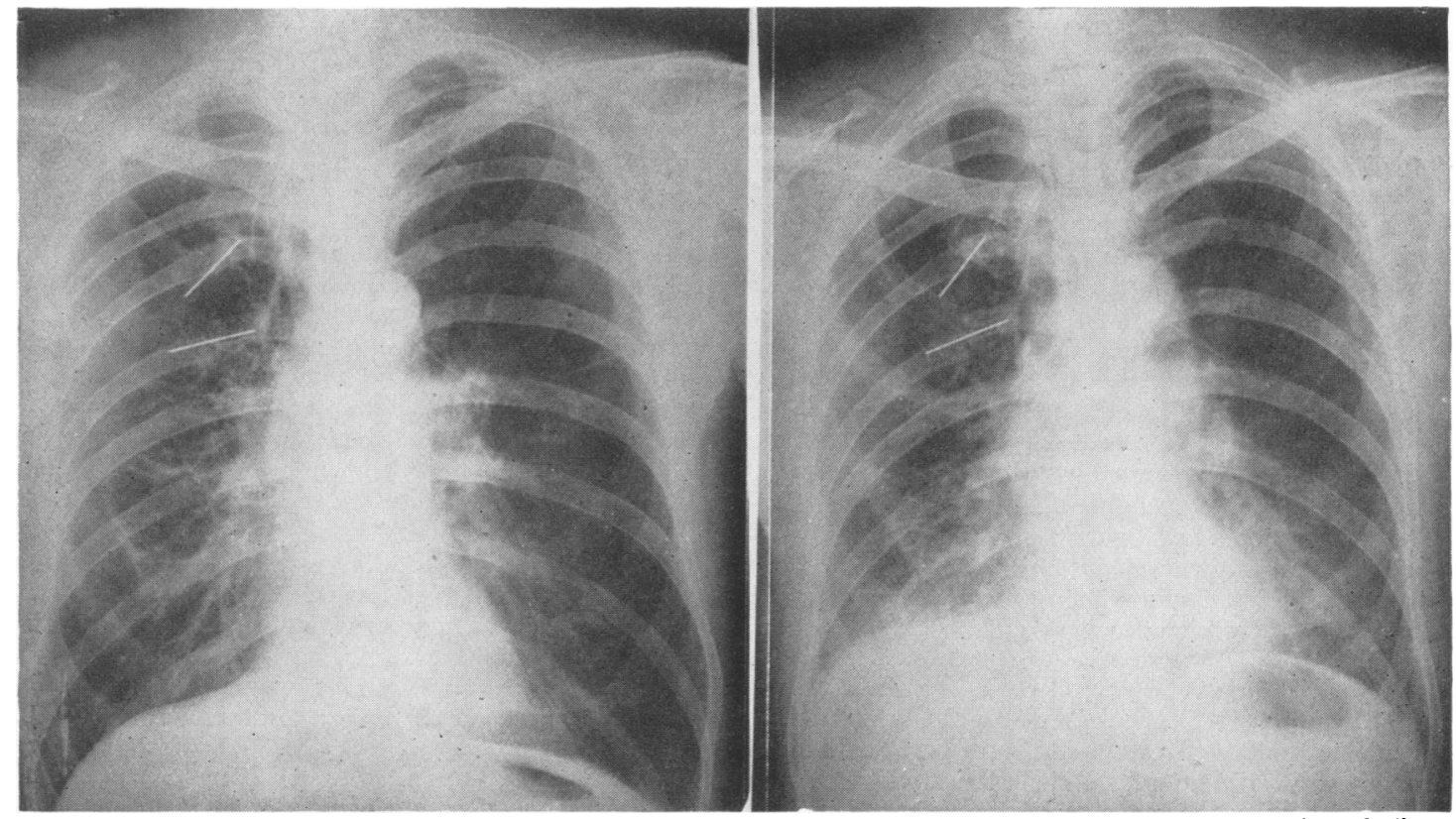

Fig. 8.-Comparative inspiration (Fig. 8a) and expiration radiographs of H. C. W. 13 months after surgical correction of disease on the right side. 
forced expiration (Fig. 8). The right lung evacuated air much better than the left. There was some tendency for the mediastinal structures to move towards the right on forced expiration. Residual focal and bullous emphysema was noted on the left side, with no evidence of progression over previous studies. The maximum breathing capacity in March, 1952, was 881 . per min., walking ventilation 251 . per min., dyspnozic index 0.28 , breathing reserve $72 \%$ (Table XIV).

TABLE XIV

COMPARATIVE VENTILATORY FUNCTION STUDIES BEFORE AND AFTER OPERATION IN PATIENT H. C. W.

\begin{tabular}{|c|c|c|}
\hline & Pre-operative & $\begin{array}{l}\text { Post-operative } \\
\text { (14 Months) }\end{array}$ \\
\hline $\begin{array}{l}\text { Maximum breathing capa- } \\
\text { city } \because . \\
\text { Walking ventilation } \quad . \\
\text { Dyspnoea index. } \quad . \\
\% \text { reserve } \frac{\text { M.B.C. }- \text { W. }}{\text { M.B.C. }}\end{array}$ & $\begin{array}{l}51.41 . / \mathrm{min} \\
26.8 \\
0.52 \\
48\end{array}$ & $\begin{array}{l}88.01 . / \mathrm{min} \\
25 \cdot 0 . \\
0.28 \\
71 \cdot 6\end{array}$ \\
\hline
\end{tabular}

This patient has been observed for two years following his operation, and has made a very dramatic recovery. $\mathrm{He}$ is able to do full arduous physical work as a farmer and is free of cough, dyspnoea, and chest discomfort.

The following patient exemplifies the localized character which hypertrophic emphysema may have with increased intra-alveolar hypertension restricted to one area despite apparent universally diffuse disease. This patient's history was as follows:

Miss B. B., 39-year-old white woman, had a family history of chronic pulmonary disease. The past history was not relevant. The history of her present illness revealed that in 1946 she developed a pneumonia which incapacitated her. It was considered to be a virus type of pneumonia and was bilateral. Following pneumonia there was an increase in cough, and marked dyspnoea, which was aggravated by an upper respiratory infection. Dyspnoea became so severe and was associated with so much wheezing that she had had to stop all work, and spend most of her time under oxygen therapy.

On physical examination the patient was in acute respiratory distress with severe restriction of mobility of the entire chest, markedly increased diameter of the chest, constant use of the accessory respiratory muscles, marked suppression of breath sounds bilaterally, and a considerable wheeze over the mainstem bronchi bilaterally. Fluoroscopic examination and inspiration-expiration radiography revealed a diffuse, hypertrophic emphysema. The diaphragms were markedly depressed and flattened. On forced expiration the right diaphragm descended $1 \mathrm{~cm}$. instead of ascending. The heart and lower mediastinum were pushed towards the left during forced expiration. The lung evacuated air poorly on either side and there was a diminution in pulmonary vascular pattern bilaterally. The patient was bronchoscoped, and a severe degree of pallor and spasticity of the bronchial tree was observed. Secretions were thick, tenacious, and mucoid. No visible cause for focal increase in obstructive emphysema on the right side could be found. The patient was so severely incapacitated as to be unable to carry out maximum breathing capacity, bronchospirometry, or walking ventilation tests. Visible and subjective improvement on the administration of intravenous aminophylline was noted.

On September 21, 1949, the patient was operated upon through a right lateral approach. Diffuse hypertrophic emphysema was noted involving all but the apical segment of the upper lobe, the entire middle lobe, and much more severely, the right lower lobe. A high right vagus nerve transection was carried out. Upper dorsal sympathectomy was done. The basilar segments of the right lower lobe were removed by clamp section. The remainder of the lower lobe was left in to act in a spacefilling capacity.

Pathological examination of the lung revealed marked hypertrophic pulmonary emphysema and moderate pulmonary fibrosis. The branches of the pulmonary arteries were moderately thickened with slight hyalinization of the media.

The patient made a dramatic recovery from the operation, and was rehabilitated sufficiently to go back to work. She was so much improved that she requested surgery on the contralateral side so that she might better participate in hiking as part of her work for the Gir Scouts. Special studies were carried out, and bronchospirometric examination was done, the findings of which are noted in Fig. 9. Following surgery and partial removal of lung tissue, there was better oxygen utilization and a larger tidal air component of the operated lung than of the contralateral lung. Maximum breathing capacity tests were done on August 3,1950, 11 months after operation, and revealed a maximum breathing capacity of 30.41 . per min., walking ventilation 13.0 1. per min., and dyspnoeic index 0.428 . The maximum breathing capacity increased to 321 . following administration of aminophylline and increased to 36.41. following administration of $250 \mathrm{mg}$. of " pronestyl." Repeat bronchoscopic examination revealed anaesthesia of the right mainstem bronchus with absence of spasm, marked hyperirritability of the left mainstem bronchus, with increased bronchospasticity.

On September 5, 1951, the patient was operated upon 을 through a left transpleural approach. Complete pulmonary plexectomy, pulmonary artery peri-arterial $\sigma$ sympathectomy, upper dorsal sympathectomy, and $N$ resection of the basilar segments of the left lower lobe N were carried out. Again the disease was noted to be somewhat localized with some fairly healthy-looking tissue in the apical posterior segment and anterior segments of the left upper lobe. Lingular segments and all segments of the left lower lobe showed diffuse? hypertrophic emphysema.

Microscopic studies of the tissue showed similar findings to those noted on the contralateral side. The patient has progressed satisfactorily since surgery. $\mathbb{D}$ Subjectively, she has noted a marked increase in pulmonary reserve. She has been able to maintain a fulltime occupation. Fluoroscopy reveals $5 \mathrm{~cm}$. movement 


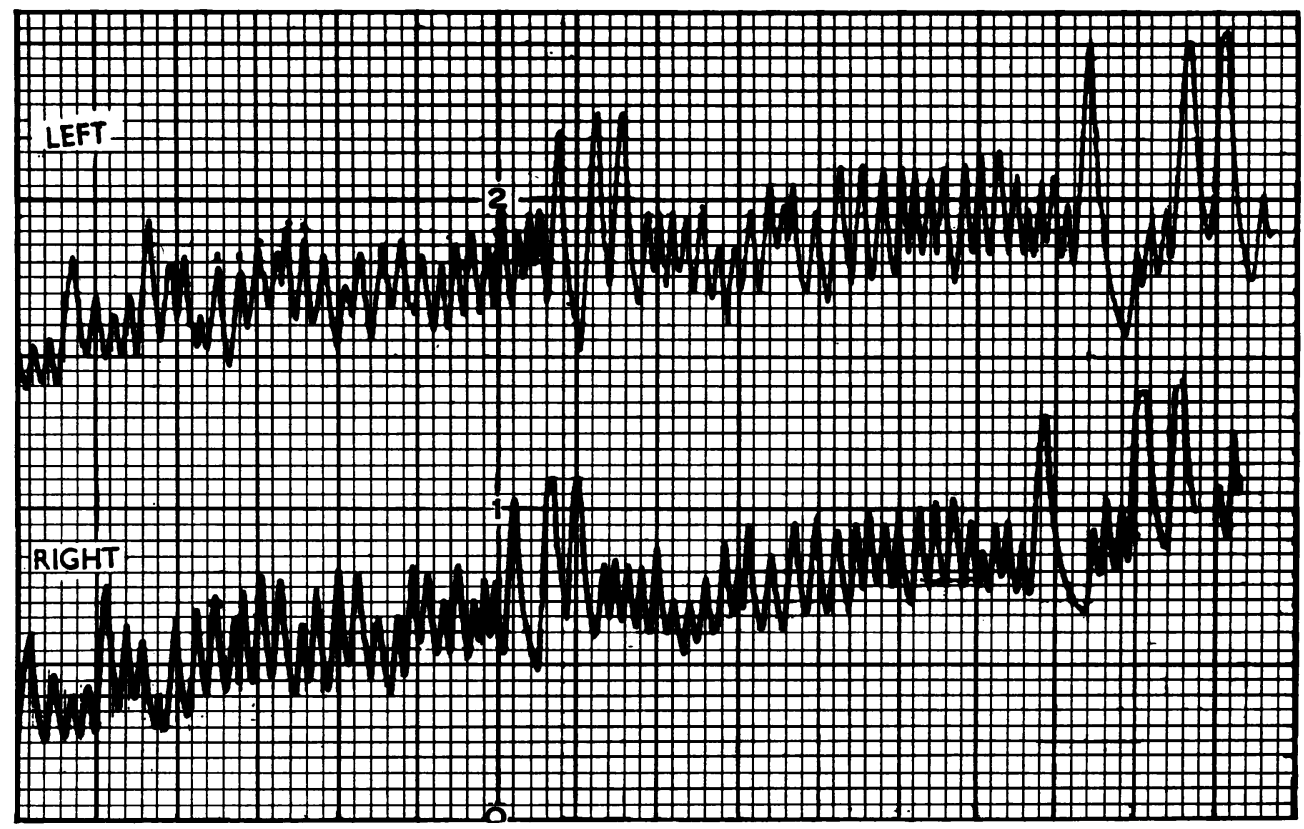

Fig. 9.-Bronchospirometric study of B. B. carried out one year after operation on right lung. The right or previously more severely diseased lung now has the better oxygen utilization ( $225 \mathrm{c} . \mathrm{c}$. as against $175 \mathrm{cc}$.). Left lung: Tidal air, $230 \mathrm{ml}$.; minute volume, 7,135 ml.; oxygen consumption per min., $175 \mathrm{ml}$.; carbon dioxide consumption per 1 . air, $42.2 \mathrm{ml}$; vital capacity, $755 \mathrm{ml}$. Right lung: Tidal air, $310 \mathrm{ml}$; minute volume, $4,965 \mathrm{ml}$; ; oxygen consumption per min., $225 \mathrm{ml}$.; carbon dioxide consumption per 1 . air, $45.2 \mathrm{ml}$; vital capacity, $755 \mathrm{ml}$.

of the left diaphragm and $3 \mathrm{~cm}$. of the right. There is now essentially uniform evacuation of air from the two sides of the chest. No shift to the mediastinum is noted during either inspiration or expiration.

This patient has now been followed up for three years since the initial operation, and has been restored from complete invalidism to a useful, busy life. The improvement in respiration was far more dramatic following the operation on the first side than on the second side. Surgical correction of localized areas of markedly increased intra-alveolar pulmonary hypertension can be expected to give dramatic results. Such an area as noted in this patient was not only disturbing pulmonary physiology, but undoubtedly also was disturbing cardiac efficiency by direct compression of the vena cava.

The next two patients present situations in which only denervation procedures could be carried out. In one a denervation procedure alone was done, while in the second a denervation procedure plus stripping of the parietal pleura was also carried out. The patients' histories are as follows:

Mrs. W. T. F., a 42-year-old white woman, had a family history and a past history of no importance. The present illness revealed recurrent right pneumothorax with inability of the lung to re-expand.

Physical examination showed decreased breath sounds over the entire chest, most marked over the right side, cough, and forced expiration capable of producing wheeze. Fluoroscopic examination revealed a small right apical pneumothorax; decreased mobility of both diaphragms; a marked granular, fluffy appearance of both lungs; marked delay in air evacuation on both sides, most marked over the right upper lung field (Fig. 10).

The right pleural cavity was aspirated and the right lung re-expanded. Pre-operative ventilatory function studies revealed a maximum breathing capacity of 32.4 1. per min.; walking ventilation, 12.41 . per min.; dyspnoeic index, 0.38 ; respiratory reserve, $61 \%$. The patient was operated upon on April 11, 1950. A right transpleural approach was used. A diffuse hobnail appearance of the lung was noted (Fig. 11). The lung appeared to be uniformly involved. A small apical bleb approximately $2 \times 3 \mathrm{~cm}$. was noted, and this was excised. It was thought that this might have been the cause of the previous pneumothorax. A complete pulmonary plexectomy was carried out. The post-operative course was satisfactory. Fluoroscopic examination one month following surgery revealed an increase in the upward movement of the right diaphragm on expiration. A more rapid expulsion of air from the right lung than the left so that the heart and mediastinum moved towards the right on forced expiration was also observed.

Five months following operation, respiratory ventilatory function tests revealed a maximum breathing capacity of 45.21 . per min.; walking ventilation, 14.51 . per min.; dyspnoeic index, 0.32 ; breathing reserve, 


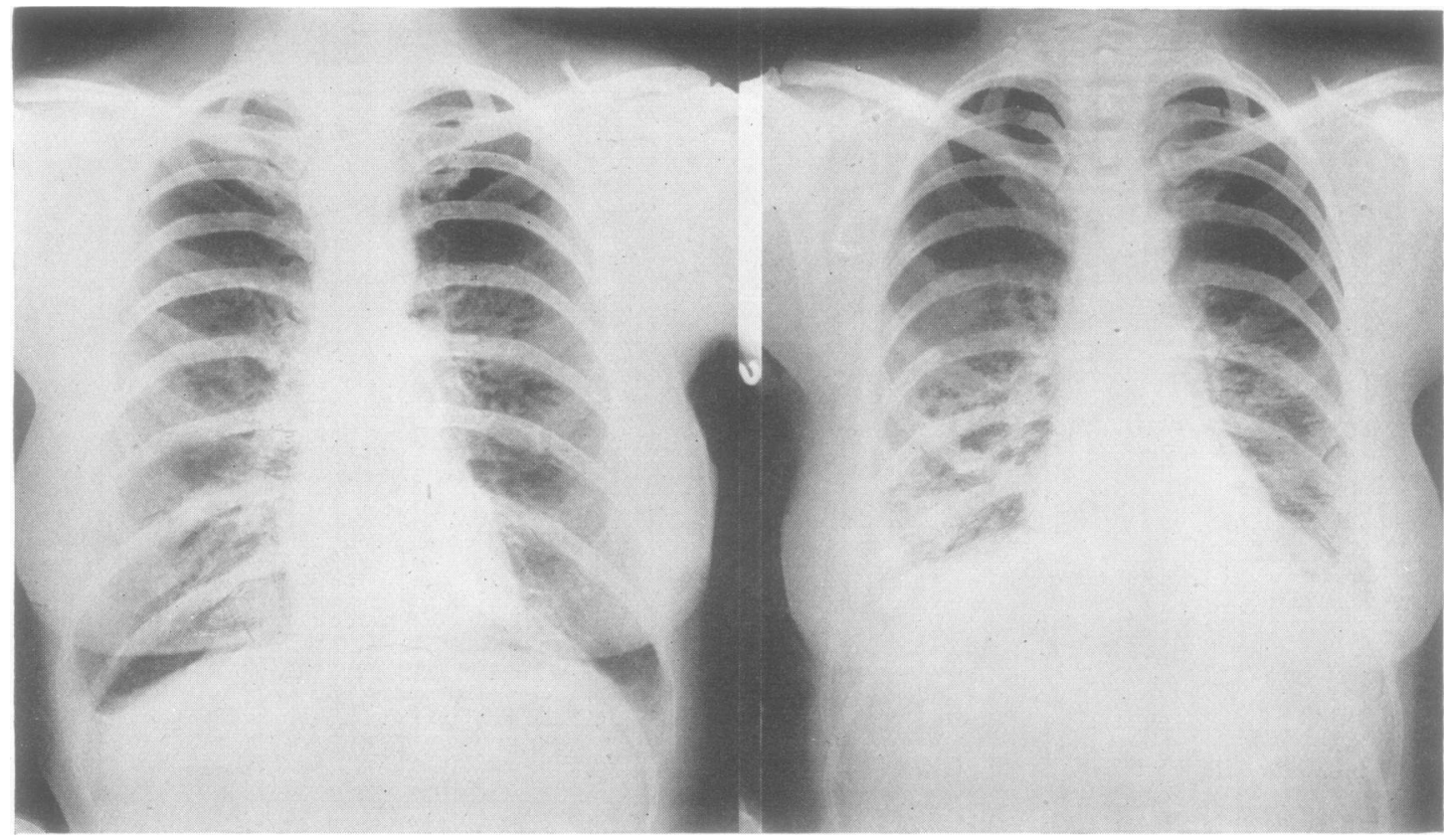

FIG. 10 -Inspiration-expiration radiographs of W. T. F. demonstrating granular fluffy areas in both lungs and fair diaphragmatic excursion

$70 \%$. The patient has shown progressive improvement since operation, and one year following operation was noted climbing a steep hill returning from a football game with apparently normal respiratory reserve. This patient exemplifies the benefit which may be obtained by denervation procedures alone in uniformly diffuse combined hypertrophic emphysema and pulmonary fibrosis.

The patient, Mr. B. G., a 60-year-old cotton-mill worker, had a family history of no importance. The past history revealed two episodes of pneumonia 35 years before. He smoked at least one packet of cigarettes a day for many years. He stopped two years ago, without major subjective benefit. He now complained of chronic cough, severe smothering, wheezing, and dyspnoea, progressive over the past 15 years. A wheeze had been noted for 14 years; cough had been more severe during the past two years; there had been extreme disability and cyanosis for the past year leading to an invalid existence.

Physical examination revealed cyanosis, respiratory distress, use of accessory respiratory muscles, audible wheezing on respiration, marked increased diameters of the chest, crackling rales heard over the entire lung field, and a distant character of breath sounds throughout. Fluoroscopic examination showed marked delay in air evacuation of both lungs, increased prominence of the main pulmonary arterial trunks bilaterally with a distinct increase in prominence of the pulmonary segment area of the cardiac contour. The right diaphragm was more flattened than the left, descended less rapidly, and ascended more slowly than the left. There appeared to be a greater delay in air evacuation of the right lung than the left. This patient was considered to have severe pulmonary emphysema, some tendency to localized increased intra-alveolar pulmonary hypertension on the right, a marked degree of pulmonary fibrosis, and early cor pulmonale.

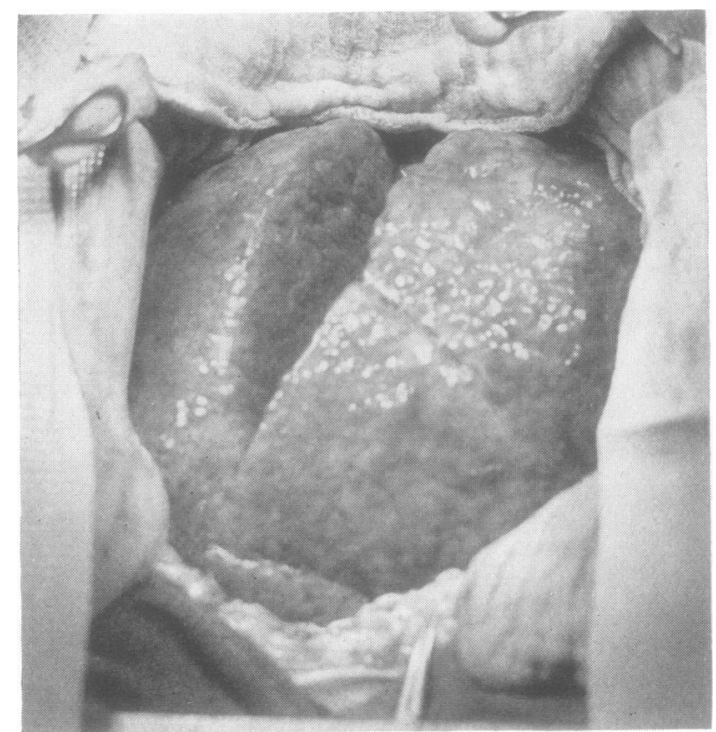

FIG. 11--Photograph of specimen of W. T. F. taken at the time of operation showing nodular almost hobnailed appearance of the right lung. 
The patient was followed closely from October 12, 1951, until July, 1952. He was bronchoscoped on numerous occasions and a severe degree of bronchospasm was noted. Some secondary suppurative bronchitis was noted, and this was treated vigorously. Chest exercises were instituted. A prolonged regimen of bronchodilators was utilized. Despite intensive treatment symptoms progressed, and he was unable to $\cdot$ lead more than an invalid existence. The patient was not benefited by digitalization. There was no increased respiratory capacity upon adequate diuretic therapy. Ventilatory function studies were carried out in March, 1951. The maximum breathing capacity was found to be 46.3 1. per min.; following the administration of aminophylline, it increased to 48.81 . per min.

It was finally decided that, despite the severe risk involved, operation was justified. On July 14, 1952, the patient was operated upon through a right lateral transpleural approach. Diffuse hypertrophic emphysema was found, with associated pulmonary fibrosis involving the entire right lung. A high right vagus nerve transection was carried out. Upper dorsal sympathectomy was done. The parietal pleura was excised, and the surface of the lung abraded with a fine powder suspension. The patient had a satisfactory post-operative course. He noted very marked subjective improvement. He was able to sleep throughout the entire night lying flat, whereas he had had to sit up during most nights before surgery, with considerable dyspnoea. He was now up and about without limitation. Eight weeks following surgery, ventilatory function studies revealed a maximum breathing capacity of 601 . per min. Following the injection of aminophylline, this decreased to 56.6 1. per $\mathrm{min}$.

This patient exemplifies the benefits which may be obtained in an individual with diffuse hypertrophic emphysema with associated pulmonary fibrosis and cor pulmonale.

\section{Summary AND CONCLUSIONS}

We have presented results of a seven-year study of 294 patients suffering from various types of pulmonary emphysema. One hundred and twenty-seven of these patients were under 50 years of age, 102 were between the ages of 50 and 60 , while 65 were over 60 years of age. This emphasizes the fact that pulmonary emphysema is not simply a degenerative disease of old age. In fact a majority of the 102 patients between the ages of 50 and 60 presented apparently healthy vascular systems, and the disease started in their $30 \mathrm{~s}$ and $40 \mathrm{~s}$. The disease was approximately three times more frequent in men than in women, and at least $46 \%$ of the patients presented a family history of similar pulmonary disease.

A study of the histories presented by the 294 patients demonstrated an almost constant history of protracted cough or so-called " chronic bronchitis." The cause for this chronic bronchial irritation was investigated. At least a single agent for such irritation was found in 288 patients, and 178 of these had a combination of two or more agents producing bronchial irritation. Major agents involved were tobacco and chronic suppuration. We are impressed with the destructive effect of tobacco in excess in these patients, and the moderate use of tobacco in certain patients who have a sensitized bronchial tree.

We have been impressed with the role of bronchospasm in the production of pulmonary emphysema. It is assumed that a combination of such spasm or hyperirritability plus oedema of the bronchial tree provides a mechanism of partial and intermittent obstruction to air evacuation from the alveoli. Unequivocal evidence of bronchospasm was presented by 267 of the 294 patients.

Analysis of the data presented emphasizes the importance of chronic bronchial irritation, bronchospasm, and an apparent inherited tendency as the components necessary to produce pulmonary emphysema, at least in the pre-senile group. We feel that the pathological changes of pulmonary emphysema are not due to an idiopathic atrophy, but are the result of prolonged partial (bronchospasm and oedema) and intermittently complete (cough) obstruction of the airway. The mechanism by which such obstruction produces spasm of the nutrient arteries by both reflex and direct compression mechanisms has been outlined. Further study of this group of patients has impressed us with the tendency of all forms of pulmonary emphysema to have an initially localized distribution. The capacity of such initial foci of disease to augment the progress of the illness has been impressive in our experience. Angiocardiographic studies and observations at the operating table substantiate this opinion. We feel that the progress or pathogenesis of the illness depends upon a continuation of the initiating sources of irritation, bronchospasm, plus the influence of primary foci of pulmonary emphysema.

From a study of a large group of patients with pulmonary emphysema, we have felt the need for a new classification of the disease which would portray the progress of the illness and could be correlated to the type of therapy required and the prognosis. Three basic types have been described, and the characteristics of each type identified. The diagnostic methods for defining localized areas of increased intra-alveolar hypertension by fluoroscopy and angiocardiography have been described. 
We have tested our concept of the aetiology and pathogenesis of pulmonary emphysema by various therapeutic regimens. All patients were initially treated by a so-called conservative regimen and the benefits noted. This gave a basis for comparison if surgery were contemplated. Sixty-seven of 189 patients treated by this regimen alone obtained a beneficial response from such therapy, and paralleled the stage in which the disease was treated. Thus 15 of 17 patients with Type I emphysema were made completely asymptomatic, while in Type III less than $30 \%$ derived any benefit. The benefit obtained from such a regimen was more dramatic where greater degrees of suppuration were present, and in those individuals in whom there was the most marked tobacco hypersensitivity. It is rare that patients with Type I disease will need anything more than this type of treatment.

We have described a surgical approach to pulmonary emphysema based upon an attempt to control the various physiological factors involved in the development and progress of the disease. An analysis of our experiences with 67 patients has been presented. There is a certain select group of patients with widespread pulmonary emphysema with scattered areas of fibrosis in whom the overall size of the lung is little enlarged, whose diaphragms work quite well and are not depressed. This group may derive startling benefits from a complete pulmonary plexectomy without tissue resection.

Resectional procedures plus plexectomy produced major and striking improvement in 21 patients with bullous and mixed types of emphysema.
Forty-six patients with the hypertrophic form of the disease have been treated surgically. Sympathectomy or vagotomy alone proved to be an ineffectual procedure. Complete plexectomy without tissue resection was beneficial in seven or nine patients, the most striking benefits being obtained in the select group previously mentioned. Tissue resection plus plexectomy produced rather uniform, striking results in patients with diffuse pulmonary emphysema in whom there was a unilateral focus of emphysema or a trigger area producing bronchial irritation. The benefits of surgery decreased as these areas presented bilaterally. Finally the group of so-called " desperation" cases with fixed emphysema, in whom little if any useful lung remains, have not benefited from surgical intervention. These findings emphasize the need for earlier diagnosis of the disease and careful selection of patients for operation.

During the course of this study it became obvious that a specific technique for the transection of lung tissue in pulmonary emphysema would be required to prevent air leaks and haemorrhagic pneumonitis. A technique utilizing the Potts' coarctation clamp has been described.

\section{REFERENCES}

Abbott, O. A., Hopkins, W. A., and Guilfoil, P. H. (1950). J. thorac. Surg., 20, 571 .

Cond Van Fleit, W. E. (1952) Experiences with a New Concept of the Etiology of Pulmonary Emphysema. Transactions of National Tuberculosis Association.

Blades, B., Feattie, E. J., Jr., and Elias, W. S. (1950). J. thorac. Surg., $20,584$.

Carr, D., and Chandler, H. (1948). Ibid., 17, 1

Crenshaw, G. L., and Rowles, D. F. (1952). Ibid., 24, 398

Hanlon, C. R., Sabiston, D., and Burke, D. R (1952) Ibid, 24, 190.

Kummell, H., Sr. (1923). Klin. Wschr., 2, 1825

Peters, R. M., and Roos, A. (1952). J. thorac. Surg., 24, 389. 